\title{
ON THE IMPACT OF THE NEW COMMUNICATIONS MEDIA UPON SOCIAL VALUES
}

\author{
Paul Baran** \\ INTRODUCTION
}

The challenge of describing the manner in which new electrical communications are modifying society and its values resembles the one facing an ant approaching an overripe watermelon: it is appetizing but overwhelming. The task is more a career than a paper. Not having comprehensiveness as a possible choice, we must settle for consideration of only a few of the directions of change which are being and will be wrought by electrical communications. To retain perspective on what follows the reader should remember that the evolving electrical communications technology is only one factor-though a major one-among many bringing on a markedly changed society. The all-pervasive nature of the more powerful communications media is unique, especially when we use the term "electrical communications" in a broad sense to include efficient use of computers and the automation of mechanical systems, both of which would be impossible if it were not for the new communications technology.

To see better where we may be going, let us assume that the technological developments in this field which seem theoretically possible today are in fact accomplished in the future. If we use the future as a vantage point we can speak from a stance which will permit us a better vision of ourselves as a society. To do otherwise is to be too close to the phenomenon. We would be like the puzzled ant who, bobbing on a leaf in a storm, wonders what is happening to his world. ${ }^{1}$ We seek to learn where our leaf is falling-or at least to learn the nature, magnitude, and direction of the winds of change.

But before we can take this broader view, we should at least attempt to satisfy our proclivity toward the more narrow-toward identifying specific developments in communications technology which even today suggest coming changes.

$\mathrm{I}$

\section{The Changing Communications Technology}

Listing such developments is not difficult. Nor would it be difficult to combine them to produce the outlines of a scenario for change. Six points in particular would stand out in this scenario:

\footnotetext{
* Institute for the Future, Middletown, Conn.

1 The recurrence of the ant simile may suggest both the author's perspective on his subject and his apprehensions about our future society.
} 
I. The full range of new communications services suggested by even the more wide-eyed people in the field generally appears to be technically possible (if oneis not overly fussy about cost).

2. If cost is a matter of initial concern, comfort is restored by noting that prices of most systems components are rapidly dropping.

3. Lack of bandwidth is not the problem most believe it to be. All the transmission bandwidth one would ever want, together with lower cost communications terminals, computers, and similar hardware, appear to be in the cards.

4. Technology is rarely a binding constraint for new communications applications in the future.

5. There are more serious, self-made constraints-lack of entrepreneurial effort, copyright laws, common carrier regulations, antiquated frequency allocations, and the like-most of them institutional issues. But even man succumbs to reason. And as he does, these impediments will erode or diminish.

6. Avoiding the question of precise dates of availability, discussions of the implications of the new communications services possible may proceed without excessive concern for technological detail.

It takes only a limited imagination to visualize the new services. Yes, we probably will have person-to-person, large-screen TV in every home. Yes, we almost certainly will have data banks and similar products of progress. Yes, we will, if we wish, have the completely portable wrist watch telephone always with us, even in our most private retreats, for those among us whose time is so important that none can be wasted in doing only one thing at a time. Rather than dwell upon the technical details of such wonderful technological blessings to mankind, consider instead their social effects-for example, the portable telephone that rings at just the wrong time, and with a wrong number.

II

The Message Is More Important Than the Medum

\section{A. We Are What We Eat}

Some nutritionists hold that the physical structure and well-being of an individual are to some degree determined by the food he eats-particularly at the earliest stages of body growth. There is a parallel in the observation that children grow socially. And this growth is to an increasing degree being derived from the mass media-especially the visual mass media. The value formation process proceeds most rapidly at the earliest stages of life. Here there are no fixed values to modify, only new ones to be added. 
In our culture we tend almost completely to ignore the scope, effectiveness, and all-pervasive social conditioning that occurs to the younger recipient of the constant barrage from the mass media. This point, which can be disputed only in its particulars, is one we shall come back to from time to time in what follows.

The immediate changes that we will discuss will include those brought about by such services as the checkless-cashless society, the bookless library, the electric plug in the home that provides access to all the world's knowledge, and similar overpublicized possibilities. The changed life patterns that may result are both more obvious and less significant than the subtle changes in society's value structure inadvertently wrought by those whose interest is to keep the channels occupied and not to worry overmuch about content.

\section{B. Message Versus Medium Effects; Random Versus Programmed Values}

It is helpful to distinguish between media effects and message effects. For example, when TV arrived, children spent a little less time reading and sleeping. This was a medium effect. But when teeny boppers watch the Beatles or Ed Sullivan's program one year and fathers wonder why in hell their sons won't get a haircut five years later-this is a message effect.

Our historic insensitivity to message effects is unfortunate. It may be the single most important factor in determining the future value structure of our society. There are several reasons for this almost universal apathy. Cause and its delayed effects are not unambiguously related; the effects are nonlinear. And we tend to hold an almost unquestioning belief that control of our media is synonymous with loss of a constitutionally guaranteed freedom proclaimed first and foremost in the Bill of Rights.

A child who watches murder on TV rarely acts out his lesson. But there is a growing, gnawing doubt about what may be happening to the child's later sensitivity to violence. But it is not clear. It is like cigarette smoking. At one time, we had reason to suspect that it probably wasn't good for you. But in the absence of "proof-positive," as the cigarette commercials once said, though in a different context, the right to smoke cigarettes remained "good." And public policy seeks to promote that which is "good." Even today, when our knowledge is more complete, the overwhelming predominance of medical evidence makes an insufficient case to reverse past beliefs. There is an escalation of the level of proof required to modify earlier decisions. Collective minds reconsider neither easily nor rapidly. While the new communications have the potential to fill the child's (or adult's) input communication channel to capacity well before we realize what has happened, we have yet to see a public appreciation that the remedy-restructuring beliefs-will be very much more difficult than creating them initially. 


\section{The Coming Showdown}

As a society we face a period of a loss of innocence when it dawns upon us that individuals are programmed to behave with a set of values acquired primarily in very early youth, and that even today the greatest input component to the formation of these values is by electrical communications. This day will not occur until we seriously consider the nature of the message between the lines of TV and other fare. Only then will we appreciate the full significance of programming designed foremost for the commercial benefit of advertisers and its impact upon the resulting fundamental values of the following generation of society. This day is probably not near because someone will first have to prove beyond a shadow of a doubt (I) that our value system is acquired and not God-given, (2) that it is very much subject to societal guidance through communications, and (3) that tampering with it is not as bad as leaving it alone.

We face a dilemma. We as a nation prefer a laissez-faire attitude toward content control of our media. This attitude may be a response to our awareness of repugnant dictatorial governments and religions which perpetuate themselves by blatantly distorting facts and conditioning values by control of information. We thus wish to believe that any development of values by accident is better than any indoctrination by governmental intent. Yet the hidden messages inflicted upon the very young are not at all random. They are sufficiently correlated (in the mathematical sense) that they possess the necessary consistency and frequency to form a potent conditioning force for value indoctrination. Of course, we are not certain of the precise nature and extent of the values being inculcated, and we therefore tend to regard program content as if it were neutral in its impact.

In the following we shall consider some of the new forces of change upon various sectors of society. We shall concentrate on communications media phenomena rather than message phenomena of the sort we have just been discussing. While the capability of message transfer is markedly increased over anything that we have yet seen, it is still the content of the message that will more substantially determine how future new electrical communications will change our life. But this cannot be understood without a better insight into the new electronics media themselves.

\section{III}

\section{Some Vignettes of Change}

The following sketches suggest the nature of changes occurring, caused in large measure by the new communications. No attempt is made to be all-inclusive.

\section{A. International Relations}

The End of the All-Evil Enemy. TV has breached the privacy needed to conduct an old-fashioned, highly dedicated war. The war in Vietnam is probably the first 
instance where this country faced an enemy not universally composed of all-evil men. Few American political leaders have ever been anxious to fight a war. To ask that it be fought in a goldfish bowl may be asking too much of them in the future.

The End of Effective Strategic Military Secrecy. Electrical signals emanating from the communications networks of each major country are fair game for remote satellite antennae. Most of the strategic military effectiveness of a closed society's secrecy is lost through transmitting information over electrical communications channels. Electrical communications channels tend to be leaky. Further, the new mass communications media which allow the public access to a wide diversity of viewpoints have made maintenance of military secrets virtually impossible. Military procedures and national laws have yet to acknowledge this reality.

Developed Countries Together-Underdeveloped Apart. The new communications capacity is not uniformly distributed. Like world wealth, "them that got, get." Conversely, those that have little may expect to get less. The more highly developed nations are also those with this new, powerful communications capacity. The underdeveloped nations have relatively less. Hence, the developed and underdeveloped nations have another divisive force to spread their interests farther apart.

\section{B. National Affairs}

Merchandising Political Candidates. Within the last thirty years, man has wrested more understanding of the techniques to change people's minds voluntarily than is found in all the tomes or rhetoric of recorded history. In a world where "technological fallout" is highly regarded, the short and obvious jump from selling soap to selling politicians will be natural and swift. Even today we see commercial organizations which will substitute, for a fee, their own pre-tested words for those of a candidate. The success of these organizations in winning an election has yet to be acknowledged by those responsible for preservation of our election process. It is embarrassing to a democracy to admit that the thirty to forty percentage points determining the outcome of a major election can be bought from public relations firms-firms that are not famous for their prudent selectivity or high ethical concerns. With better communications and computers these distorters of reality have increasing power to create candidates and to reach new heights, or depths, of subtle demagoguery: Starting with lots of money, they can buy an actor, add makeup, program him with a computer-prepared script based upon the populace's latest fears (earlier induced by the same mass electrical communications), and broadcast ten-second film clips ad nauseam until the polls predict success.

The Demonstration in Lieu of the Vote. This coupling of financial and electronic resources to win elections has a possibly not accidental parallel in the new use of the violent demonstration as a force to subvert representative democracy. One game is 
for the rich, while the other is open to all irresponsible comers, but both reflect the understanding that to preserve or to change institutions requires political power.

In a highly communicative world, access to the communications broadcast resource is partially equivalent to political power. The temptation for national governments to exercise power by controlling the communications media is old stuff-but not in the United States. However, the sale of TV time for political advantage is equivalent to a conversion of economic power into political power. Similarly, TV's insatiable appetite for visible dramatic news provides the mechanism whereby the demonstration-or, more accurately, the staged riot-can convert political zeal and energy into political support by galvanizing sympathies or inspiring fears and guilt.

TV news today is a form of entertainment. Entertainment seeks audience size. The visually dramatic overweighs balance and importance. The staged riot is remarkably cheap for the rioters. In "cost effectiveness" jargon it allows a maximum return of political power at lowest dollar investment cost if the issues of long-term societal costs are ignored. By its nature the tactic of staged riot seems reserved for minority use, though the majority has an analogous advantage in the availability of free and purchased TV time for its own activities.

A New Difficulty in Achieving National Cohesion. A stable national government requires a measure of cohesion of the ruled. Such cohesion can be derived from an implicit mutual agreement on goals and direction-or even on the processes of determining goals and direction. With the diversity of information channels available, there is a growing ease of creating groups having access to distinctly differing models of reality, without overlap. For example, nearly every ideological group, from the student underground to the John Birchers, now has its own newspapers. Imagine a world in which there is a sufficient number of TV channels to keep each group, and in particular the less literate and tolerant members of the groups, wholly occupied? Will members of such groups ever again be able to talk meaningfully to one another? Will they ever obtain at least some information through the same filters so that their images of reality will overlap to some degree? Are we in danger of creating by electrical communications such diversity within society as to remove the commonness of experience necessary for human communication, political stability, and, indeed, nationhood itself? Must "confrontation" increasingly be used for human communication?

National political diversity requires good will and intelligence to work comfortably. The new visual media are not an unmixed blessing. This new diversity causes one to hope that the good will and intelligence of the nation is sufficiently broad-based to allow it to withstand the increasing communication pressures of the future. 
The Temptation of Instant Plebiscite. Today, most politicians rely on political polls to some measure. There is a potentially unwholesome communications development possible in the improvement of techniques to carry on such polls. We could, if we wish, have the technical capability to poll instantaneously all interested TV viewers to obtain an opinion profile on any issue put before the nation. What underlies the concern about such a development is the almost religious belief among some that everything shown between the commercials on TV is the truth. The subtle differentiation between the image of reality and reality itself is too easily lost when only parts of an issue are selected for presentation. TV writers worship simplicity as a factor contributing to audience size, but a well-staged TV show can nevertheless make many people believe not only that what they have seen is the truth but that they have seen the whole truth. Further, TV audiences probably select themselves on something other than a random or representative basis. These doubts about induced or inherent biases on the part of an electorate assembled by television suggest the dangers of immediate-response polling. From a distance, the restoration of the town-meeting principle by electronic ingenuity may seem to be a normal extension and improvement of the democratic process. But the short fuse of quick response does not allow room for error or for accommodation of majority and minority rights.

We will probably not move into the electronic plebiscite overnight. But the technology is near for a drift in this direction in an evolutionary manner. For example, instant electronic polling on TV will be economically useful for both advertising agencies and politicians in designing their campaigns, and without legislation to prohibit polling the views of large groups, it will seem natural to increase sample size to larger and larger audiences. If there are pushbuttons, they will be pushed, and if some do not have buttons, they will feel underprivileged and impotent. The next step, pushbuttons for all, becomes a plausible evolutionary development, and the last step-if nothing is done to prevent such an outcomeis probably to connect the pushbuttons to the action machine. Our present lack of appreciation of the dangers of this form of political representation is a reminder of our generally poor understanding of the potentialities of electrical communications and their effects on democratic processes.

\section{Local Government}

The End of the Boundary-Walled City. With an increasing number of the tasks of the work day performed over communications circuits, there is a lessening need for people to congregate together to conduct the business of the world. The circle in which potential person-to-person conversation is possible increases when physical presence is not required. All who speak the same language in the world of electrical communications become neighbors, regardless of geographical distance. A new worldwide city of ideas is created whose boundaries do not coincide with the 
historic limits of the city. Tall office buildings will no longer be required as proximity becomes less and less a function of geography. The new communications capability will blur the distinction between urban and suburban existence.

The eventual large-scale substitution of communications for transportation is sufficiently predictable to require total re-examination of our concept of the city and its growth. When the full impact of the substitution is felt, it could mean the elimination of much which the city of today offers, indeed of its very raison d'être-ease of communications and transportation and access to more people and activities than is possible in a less dense area. Present cities could become as uneconomic and as anachronistic as the small farm in the era of the mechanization of agriculture. Left almost solely to the uses of those who cannot fully participate in the communications revolution the cities may become more povertyridden than we currently anticipate. Those whose assets are tied to the large city may have a more precarious investment than they realize.

Lack of a Feedback Channel. Techniques to inform the public about what the government is doing are improving. Even today we overload or satiate most citizens with information on what the mayor is or is not doing. This is downward communication. One of the most pressing communications needs is for a good upward channel. For example, the slum dweller who listens and sees the mayor talking to him on television lacks any effective channel of communication upward to ask the mayor why his garbage has not been collected, or why the dope peddlers are so thick in his apartment lobby that he can hardly get into his own apartment.

This flood of news flowing downward and the felt lack of an upward channel of reply can be expected to worsen in the near term. We need an information feedback channel to assure the citizen that his specific message (not the group response) has, in fact, been received by the power structure. Failure to supply such a channel would appear to guarantee alienation from the political process. No one has yet seriously considered providing the ombudsman junction electrically. Yet in the large cities it may be the only realistic course open.

\section{Vocational Pursuits and Power Structures}

The Erosion of Routine Administrative and Clerical Functions. The nature of employment is changing. An increasing portion of the average employee's day is spent on information transfer, and less on the physical production of goods. Better electrical communications and computers could allow increasing automation of administration and clerical functions. Many middle and lower middle management personnel may be expected to follow the clerks and production workers on their way out as their information-gathering and dissemination functions are assumed by computers linked to the outside world by the new communications. This is not to say that unemployment will result, only that major shifts of employment patterns 
will occur. New jobs will open as old ones disappear. For example, consider the following:

Elimination of the Middleman in the Information Process. Many of today's jobs are concerned with distorting information presented to the consumer. Slipperytongued salesmen survived the invention of electrical communications, although their functions have been somewhat altered in the electronic age. The newer electrical communications between producer and consumer can reduce the need for some such middlemen. For example, the new electrical capability could allow precise price, specification, and delivery information to be given directly to the consumer by the computer, thus eliminating the need for some of today's salesmen. If so, the salesmanship of the future will have to be much more subtle-as puffing will be more readily subject to checking. In the future we will have the technical capability-whether or not it is used is another matter-to obtain the facts needed for better product comparison than today. We may even anticipate that manufacturing organizations will choose to sell products directly to the individual consumer, utilizing two-way TV connections and reducing the role of the army of intermediaries. New product comparison services, which can be addressed at the time of the selection decision, can be made economically viable with the new communications.

There is a remarkable number of other jobs that might be eliminated or modified by reliable, cheap communications and a well-programmed computer. Even an entire profession could be made obsolete. For example, the pharmacist, who in this age largely relabels packages or medicines, now serves little useful purpose other than as a check on the physician's honesty, a job that computers might adequately perform. Computer diagnosis and patient monitoring, often carried out by distant computers accessible by communications networks, may greatly change medical practice, perhaps eliminating nurses' jobs and freeing doctors for other pursuits.

Communications developments also threaten the "middle management" of society's past value-setting organizations: the clergy and the teachers. Even today the local clergyman does not seem nearly so all-knowing as he did during the last century. The diversity and often greater wisdom exhibited by a plurality of alternative commentaries on morals-on the radio and TV-is powerful competition. The work of the clergyman, as a distributor of moral wisdom, and of the teacher, as a dispenser of education, has to some degree already been displaced by electronic channels. If it were not for their continuing service as an "upward" communications channel, many of these would have already been forced to turn to other endeavors. In the future, we may expect to see representatives of the familiar old professions, but their actual roles may have drastically changed from that of esteemed professionals. 
One wonders if career choices of the young are adequately informed by an awareness of the impact of the new communications and the computer.

The Richest Man in the Future World. As communication development evolves, more decision functions will be placed upon computers tied together as a common communications network. Financial success may in the future come to depend more upon the brilliance and imagination of the human who programs the computer than upon any other single factor. The key man in the new power elite will be the one who can best program a computer, that is, the person who makes the best use of the available information and the computer's skills in formulating a problem. In a world where knowledge is power, and where communications mean access to power, he who can most effectively utilize this access will be in the driver's seat. Some persons (primarily computer programmers) claim that the richest man in the world in the year 2000 will be a computer programmer. This may sound outlandish, but few really good programmers laugh when they consider this assertion.

\section{E. Education and Leisure}

Revised Role of the School-Admitting to the Baby-Sitter Role. The new communications media, coupled with computers, will be capable of presenting more subject matter than the student can ever be fed in conventional schooling. However, this does not mean the demise of the conventional school and the substitution of the home TV screen. The teacher can still perform functions which we have not yet learned to automate, such as baby-sitting. Few parents will willingly pass up such cheap, safe baby-sitting services. It remains to be seen whether teachers will assume a greater role in the interpersonal educational experience and thus avoid technological obsolescence. Here, the human teacher has advantages that cannot be matched by a communications device.

The New Leisure. If historic trends continue, most individuals will have more disposable time and income. Some students of this trend look toward the computer/ communications network to absorb the surplus hours and dollars. Recreation via communications lines may turn out to be a major use of the computer of the future. TV games could allow the viewer to participate by telephone/TV, thus enlarging the audience from a few chosen from the in-person audience to all the viewers, perhaps with an intensification of interest.

This new capability for masses to interact in gamelike fashion with a remote computer occurs at a time when the ability to flood people "downward" with information has exploded. Recreation via computers will be one of the few "upward" channels open to all. There is a strong emotional need for the feedback channel in most "electrical communications crowds" to allow people to interact with something. 
The Small Group Broadcast. In this new world, individuals with common interests but who are geographically separated can "come together" to discuss or share topics of mutual interest. Everyone, no matter how small his physical community, will be potentially a part of an audience having a more specialized interest than any that can be assembled in any large city today. With the improving communications capability in the future, it will be economic to have smaller and smaller audiences for specialized programs. As institutional barriers to "pay-TV" are overcome and channel space becomes available, untapped markets will be reached, with benefits for all. In addition to theater, ballet, opera, "art" films, lectures, and other activities having less than mass appeal, who knows? We may have small groups around the country using electrical communications of the future to share a common interest in some particularly novel form of pornography. Don't dismiss the idea completely. Nature abhors an empty communications channel.

Living with the Information Overload. Excessive communications could mean a world of too many acquaintances, too few friends, an absence of tranquility, and a life of motion, frantic even by today's standards. Just as the nation is becoming intolerant of air, water, and noise pollution, the next generation may regard information overload not as a God-given process but as a controllable price of civilization. There are signs today of increasing concern for privacy and freedom from intrusion by undesired communications. Some believe that a desire exists for filtering and protective devices to cope with the deluge of requests for attention. For example, selectable telephone ringing signals could allow a caller to say that his call is not urgent, in the event the called party is in the tub, or otherwise occupied.

Without such efforts toward adjustment, we might find a revulsion developing toward an excess of communications. Before this happens, we can hope that those who supply communications channels appreciate the all-pervasive nature of their service and develop new filtering techniques.

\section{Postscript}

The new communications is like fire, neither villain nor hero. While its role will depend on how it is used, not understanding how it works is indeed equivalent to playing with fire, for its potential for both good and harm is awesome. As an observer, I must confess I am becoming uncomfortable. This may be too powerful a social force to be left to chance in the hope that it will not be abused. 